\title{
Physician income: a look behind the numbers
}

I n Canada, the topic of physician income is probably discussed more often during contract negotiations between provincial governments and medical groups than at any other time. The figures bandied about during these at-times-heated discussions typically come from the Canadian Institute for Health Information (CIHI), and ensuring the numbers are accurate and comprehensive is no easy task.

"We have an ongoing relationship with both the ministries of health and medical associations to provide that information to both parties for negotiations of fees," says Geoff Ballinger, manager of physician information for CIHI. "We have been trying very hard to develop the data that would support that work, and it has been a challenge."

In 2013, CIHI reported that the average gross clinical payment per doctor was $\$ 328000$ a year. In Ontario, the Ministry of Health and Long-Term Care pegs average gross billings for the province's doctors at \$354 000 for 2013/14. The Ontario Medical Association, which is currently at odds with the government after failed negotiations, is quick to point out that, because of average overhead costs of $30 \%$, billings do not equal income so don't "let the spin confuse you."

The task for CIHI, however, is to improve the numbers, not spin them. In the mid-90s, when it took over collecting payment data from Health Canada, almost all physicians were paid via feefor-service. Over the years, though, there has been a steady increase in alternate forms of payment, such as salary or contract. Now as much as $30 \%$ of payments are outside fee-for-service, making it more difficult to ascribe specific amounts to specific doctors for specific services.

"We are working with provinces to try to get their alternate-payment information at the same level of detail as fee-for-service information so we can integrate those two sets of data to produce comprehensive indicators," says Ballinger. "Collecting that information has been our biggest challenge over the past decade, and we are beginning to have some success."

Currently, CIHI is receiving alter-

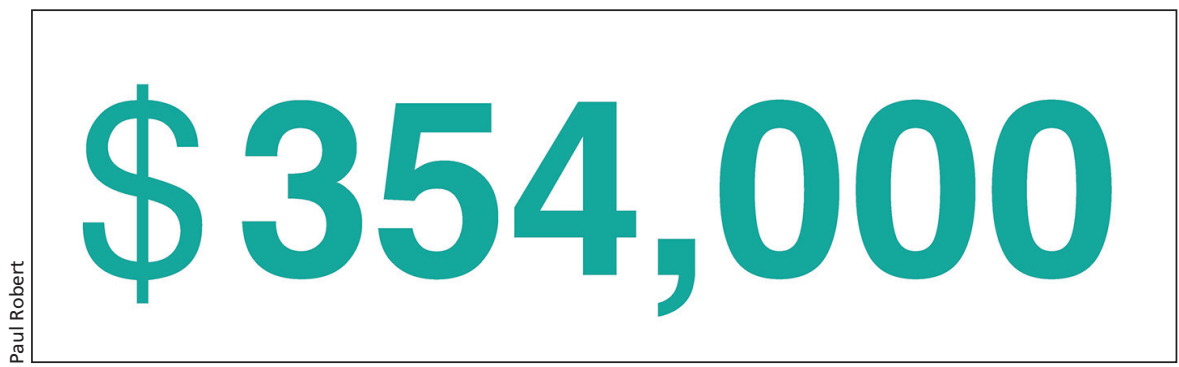

This is the average gross billing figure for an Ontario doctor, according to the Ontario government. Some doctors say that number, which doesn't account for overhead costs, does not accurately reflect their actual incomes.

nate-payment data from only six provinces, though it is expecting data soon from Quebec as well. It is not yet receiving the information from Alberta, Manitoba or Saskatchewan, though some have expressed interest in providing it.

Though alternate payments are harder to track, collecting fee-for-service data still poses challenges as well. "Every province has a different fee schedule, and we have to go through a lot of hoops to try to ensure it is as comparable as possible from province to province," says Ballinger. "That is where the complexity is for us."

Of course, it is also possible for doctors to make money outside of the clinical work for which they bill provincial governments. A practising clinician could also work in academia, or in administration, or conduct research or laboratory tests.

"It is a struggle to understand those streams," says Ballinger. "Some smaller communities trying to attract physicians may also offer other incentives, such as membership at a country club, and nobody really knows how much those things are worth."

Some physicians also have entrepreneurial streams of income. They may sell vitamins or skin creams, for example, or offer simple cosmetic procedures. Overall, though, these types of on-the-side activities don't seem to be that common.

"I don't think a lot of doctors have a private line of business," says Dr. David Henry, a senior scientist with the Institute for Clinical Evaluative Sciences (ICES). "They may well be doing occasional medical examinations for private companies, or whatever it is, under some sort of contractual arrangement, but I would say most specialists are pretty busy and don't have a lot of time. There are certainly going to be areas where there are people injecting Botox or doing some sort of wellness clinic, but it wouldn't be a huge amount, and it would be in a concentrated number of specialities."

Some doctors receive money from the pharmaceutical industry for consulting, advising or giving speeches. Again, however, this doesn't seem to be as lucrative an option as in some other countries. "From what I understand, the sums of money are not in the order that you see in the United States, where somebody might be grossing $\$ 100000$ or $\$ 150000$ a year from their industryrelated activities, quite separate from what they are getting from their teaching hospital or university," says Henry. "I'm less concerned about the actual dollar amount than about whether those ties are affecting that doctor's practice, both the research and clinical practice."

So it turns out that the seemingly simple question of how much a Canadian doctor makes isn't so simple after all. "The reality is that there is a distinct lack of clear information," Globe and Mail health reporter André Picard noted in a 2013 column. Problems include exaggerated claims of overhead expenses and taxes, as well as the paucity of data on how many hours doctors actually work. "But what doctors are paid should not be a guessing game," he wrote. "The lack of transparency does not serve taxpayers or the medical profession." - Roger Collier, CMAJ

CMAJ 2015. DOI:10.1503/cmaj.109-4997 